\title{
Healthcare-associated fungal outbreaks: New and uncommon species, New molecular tools for investigation and prevention
}

\author{
Marie-Elisabeth Bougnoux ${ }^{1,2,3}$, Sophie Brun ${ }^{4,5}$ and Jean-Ralph Zahar ${ }^{6,7^{*}}$
}

\begin{abstract}
Outbreaks of healthcare-associated fungal infections have repeatedly been described over recent years, often caused by new or uncommon species. Candida auris, a recently described multidrug-resistant yeast species, is certainly the most worrisome species having caused several severe healthcare outbreaks of invasive infections, on four continents. Also, large nosocomial outbreaks due to uncommon fungal species such as Exserohilum rostratum and Sarocladium kiliense, were both linked to contamination of medical products, however the source of another outbreak, caused by Saprochaete clavata, remains unresolved. Furthermore, these outbreaks identified new populations under threat in addition to those commonly at risk for invasive fungal infections, such as immunosuppressed and intensive care unit patients. All of these outbreaks have highlighted the usefulness of a high level of awareness, rapid diagnostic methods, and new molecular typing tools such as Whole Genome Sequencing (WGS), prompt investigation and aggressive interventions, including notification of public health agencies.

This review summarizes the epidemiological and clinical data of the majority of healthcare-associated outbreaks reported over the last 6 years caused by uncommon or new fungal pathogens, as well as the contribution of WGS as support to investigate the source of infection and the most frequent control measures used.
\end{abstract}

Keywords: Healthcare-associated fungal outbreak, Candida auris, Exserohilum rostratum, Sarocladium kiliense, Saprochaete clavata, Prevention, Whole genome sequencing

\section{Background}

Until the last decades, only a small number of fungal pathogens such as Aspergillus, Candida, Pneumocystis jirovecii, and Mucorales have been involved in healthcare-associated fungal outbreaks [1-3]. Furthermore, these outbreaks were limited to well-defined at-risk populations. Indeed, neutropenic patients, including patients treated for acute leukemia, severely ill patients during their stay in intensive care unit (ICU), and neonates hospitalized in neonatal ICU, were the main populations that suffered from these severe infections [4]. The occurrence of sporadic episodes related to other

\footnotetext{
* Correspondence: jrzahar@gmail.com; jean-ralph.zahar@aphp.fr

${ }^{6}$ Département de microbiologie clinique, unité de contrôle et de prévention du risque infectieux, Hôpital Avicenne, Groupe Hospitalier

Paris-Seine-Saint-Denis, Assistance Publique - Hôpitaux de Paris (APHP), Bobigny, France

${ }^{7}$ IAME, UMR 1137, Université Paris 13, Sorbonne Paris Cité, Paris, France Full list of author information is available at the end of the article
}

fungal species and other less immunocompromised populations remained a rare phenomenon.

Nevertheless, several recent reports have highlighted the emergence of new healthcare-associated outbreak phenomena due to fungal species previously unknown or uncommon in clinical practice. Interestingly, these fungal outbreaks affected both weak patients and healthy individuals.

Thus, a new species of Candida, Candida auris, has been recently identified and is now considered a notorious healthcare-associated yeast causing invasive infections with high treatment rate failures [5]. Diversely, during the past 6 years, rarely isolated fungi have been involved in healthcare-associated outbreaks; among these, Exserohilum rostratum and Sarocladium kiliense were related to contamination of medical products and represented a high public health threat. Also, others healthcare-associated 
outbreaks due to uncommon fungal species, such as Saprochaete clavata, are still unresolved as no source of contamination has yet been documented.

Increased vigilance and usage of advanced technologies are needed to rapidly identify the likely sources of these infections in order to efficiently guide epidemiological investigations and initiate appropriate control measures.

Since many publications have so far been interested in classical fungal infections, we aim to decipher the most notable healthcare-associated outbreaks caused in the last 6 years by uncommon or new fungal pathogens (summarized in Table 1). In order to highlight the most recent insights related to these outbreaks, we focused on (i) the epidemiological, clinical, and microbiological data, (ii) the contribution of the WGS typing method for outbreak investigation, and (iii) the recommendations to manage cases and control transmission of these uncommon fungi in healthcare facilities.

\section{Main text}

Epidemiology and clinical presentation of recently reported healthcare-associated fungal outbreaks due to New or uncommon fungal species

\section{Candida auris}

Over the past 6 years, Candida auris, a multidrugresistant (MDR) Candida species, has emerged on four continents as a yeast associated with hospital outbreaks with high rates of clinical treatment failure. C. auris causes invasive infections in severely compromised patients, is mostly resistant to fluconazole and exhibits variable susceptibility to other azoles, amphotericin B, and echinocandins. Unlike other Candida species, $C$. auris seems to have a high propensity for patient-topatient transmission in healthcare settings, possibly related to environmental contamination, or transient person or device colonization [6].

The serious threat posed by C. auris prompted the US Center for Disease prevention and Control (CDC) to issue an alert in June 2016 addressed to healthcare facilities on notifying cases of $C$. auris to local or public health authorities [7]. Public Health England also published guidelines for actively identifying and reporting C. auris to prevent its nosocomial transmission [8] and the European CDC (ECDC) [9] issued a health alert for strict vigilance of $C$. auris cases.

C. auris was first described in 2009 from a patient's ear swab in Japan [10]. The first three cases of nosocomial bloodstream infections related to $C$. auris were described in South Korea in 2011 [11]. These three cases highlighted the feature of persistent candidemia despite fluconazole and amphotericin B therapy. Thereafter, in a short span of 6 years, cases of $C$. auris fungaemia and deep-seated infections have been reported from hospitals across four continents [9]. C. auris is probably underdiagnosed as this yeast is often phenotypically misidentified as Candida haemulonii, Candida famata, or Candida sake by commercial biochemical identification systems [12,13].

C. auris causes infections in patients, ranging from neonates to elderly, with well-recognized risk factors for invasive candidiasis. Indeed, among the $41 C$. auris deep infections observed during 2012-2015; 73\%, occurred in patients having a central venous catheter (CVC), 61\% with a urinary catheter, $51 \%$ had undergone recent surgery, and $41 \%$ had diabetes mellitus [14]. Moreover,

Table 1 Healthcare-associated outbreaks due to four new or uncommon fungal pathogens

\begin{tabular}{|c|c|c|c|c|c|c|c|c|}
\hline Species & Year & Country & $N^{\circ}$ of cases & Infection sites & $\begin{array}{l}\text { At risk } \\
\text { population }\end{array}$ & Source & $\begin{array}{l}\text { Main preventive } \\
\text { measures }\end{array}$ & References \\
\hline Candida auris & Since 2011 & $\begin{array}{l}\text { Four } \\
\text { continents }\end{array}$ & $>500$ & $\begin{array}{l}\text { IFI and } \\
\text { colonization }\end{array}$ & $\begin{array}{l}\text { Risk of invasive } \\
\text { candidiasis }\end{array}$ & $\begin{array}{l}\text { Human and } \\
\text { environmental } \\
\text { surfaces }\end{array}$ & $\begin{array}{l}\text { Improve hand } \\
\text { hygiene } \\
\text { Contact isolation } \\
\text { Improve } \\
\text { environmental } \\
\text { desinfection }\end{array}$ & {$[3-14,36-50]$} \\
\hline $\begin{array}{l}\text { Saprochaete clavata } \\
\text { (formerly Geotrichum } \\
\text { clavatum) }\end{array}$ & $\begin{array}{l}\text { Sept 2011- } \\
\text { Oct } 2012 \\
\text { Oct-Dec } 2014\end{array}$ & $\begin{array}{l}\text { France } \\
\text { Italy }\end{array}$ & $\begin{array}{l}30 \\
3\end{array}$ & $\begin{array}{l}\text { Blood and } \\
\text { colonization } \\
\text { Spleen, liver, } \\
\text { lung }\end{array}$ & $\begin{array}{l}\text { Hematological } \\
\text { malignancies } \\
\text { Hematological } \\
\text { malignancies }\end{array}$ & $\begin{array}{l}\text { Unknown } \\
\text { Unknown }\end{array}$ & $\begin{array}{l}\text { Define and } \\
\text { identify at risk } \\
\text { population } \\
\text { Search for a } \\
\text { common source }\end{array}$ & [15-17] \\
\hline $\begin{array}{l}\text { Sarocladium kiliense } \\
\text { (formerly Acremonium } \\
\text { kiliense) }\end{array}$ & $\begin{array}{l}\text { June 2013- } \\
\text { Jan } 2014 \\
\text { Nov } 2013 \\
\text { March- } \\
\text { May } 2011\end{array}$ & $\begin{array}{l}\text { Chile } \\
\text { (8 hospitals } \\
\text { in Santiago) } \\
\text { Colombia } \\
\text { Greece }\end{array}$ & $\begin{array}{l}67 \\
16 \\
3\end{array}$ & $\begin{array}{l}\text { Blood } \\
\text { Blood } \\
\text { Blood }\end{array}$ & $\begin{array}{l}\text { Chemotherapy } \\
\text { Chemotherapy } \\
\text { Stem cell } \\
\text { transplantation }\end{array}$ & $\begin{array}{l}\text { Antinausea } \\
\text { ondansetron } \\
\text { (company A) } \\
\text { Ondansetron } \\
\text { (company A) } \\
\text { CVC }\end{array}$ & $\begin{array}{l}\text { Recall of all } \\
\text { ondansetron } \\
\text { lots of the } \\
\text { company A }\end{array}$ & [21-23] \\
\hline Exserohilum rostratum & $\begin{array}{l}\text { Sept 2012- } \\
\text { Oct } 2013\end{array}$ & $\begin{array}{l}\text { USA } \\
\text { (20 states) }\end{array}$ & 751 & $\begin{array}{l}\text { Paraspinal/ } \\
\text { spinalMeninges } \\
\text { Peripheral joint }\end{array}$ & $\begin{array}{l}\text { Epidural/ } \\
\text { paraspinal } \\
\text { injection of MPA }\end{array}$ & $\begin{array}{l}\text { MPA } \\
\text { (compounded } \\
\text { drug) }\end{array}$ & $\begin{array}{l}\text { Recall of the } 3 \\
\text { contaminated lots }\end{array}$ & {$[24-28,33-35]$} \\
\hline
\end{tabular}


approximately $41 \%$ of patients were prescribed antifungal therapy when $C$. auris was isolated [14]. The median time from admission to infection was 19 days (range 9-36), and $61 \%$ of patients had a bloodstream infection. The overall crude in-hospital mortality rate of $C$. auris candidemia ranges from 30 to $60 \%$ [6].

Between April 2015 and July 2016, the first European nosocomial outbreak, was described in a London cardiothoracic center [15], where $50 \mathrm{C}$. auris cases (average age 53 years, range 19-78) were reported. Among them, $44 \%(22 / 50)$ developed possible or proven infection with a $18 \%(9 / 50)$ candidemia rate, also some cases occurred despite treatment with echinocandins.

Moreover, the ECDC reported an outbreak of $33 \mathrm{C}$. auris bloodstream infections that occurred in 2016 in the surgical ICU of a hospital in Spain. One case of $C$. auris isolated from a blood culture was also reported in November 2015 by the German national reference center for invasive fungal infections. Finally, one case of invasive candidiasis, due to an isolate of $C$. auris, was also reported in Norway, but the infection was probably acquired abroad as the patient concerned was transferred from a hospital outside of the European Union [16].

A large majority of $C$. auris isolates are fluconazole resistant (93\%), and amphotericin B and echinocandin resistance rates are approximately $30-40 \%$ and $5-10 \%$, respectively. Almost half of isolates are MDR (resistant to two or more antifungal classes), and a small percentage are pandrug resistant [17]. Therefore, $C$. auris infections pose a serious challenge regarding identification and therapy, especially in developing countries where modern identification facilities (molecular identification and MALDITOF mass-spectrometry) and access to antifungals other than fluconazole are limited.

\section{Saprochaete clavata}

Several cases of rapidly fatal infections due to the fungus Saprochaete clavata, formerly Geotrichum clavatum, were reported in France within a short period of time in three health care facilities, suggesting a common source of contamination [18]. Thus, between September 2011 and October 2012, a nationwide alert collected 30 cases of invasive infections in 14 centers, including an outbreak of 18 cases over 8 weeks in 10 health care facilities located in 10 different French regions. The French alert was internationally relayed by the ECDC and CDC but no other country was concerned [19].

Half of the 30 cases reported in the French outbreak were male patients with a median age of 63 years. Most of the patients $(70 \%)$ were hospitalized for acute myeloid leukemia, were exposed to cytarabine (80\%), and all cases received blood products. S. clavata was recovered from blood in $87 \%$ cases $(26 / 30)$, from bronchoalveolar fluid or tracheal aspirates in $40 \%$ cases (12/30), and 60\% of patients had gut colonization. Moreover, diarrhea previous to or associated with fungemia was reported for $61.5 \%$ of cases, suggesting the role of a subsequent gut translocation in the occurrence of these bloodstream infections. The case fatality rate at day 60 was $80 \%$, with death occurring at a median of 7 days following diagnosis [18].

Phylogenetic analysis of the French outbreak identified a single clone (clone A) which accounted for 16 of the 18 outbreak cases and that was distinct from sporadic isolates [18]. This finding provides additional, although not definite evidence, for a common source of contamination in this health care facility outbreak. However, epidemiological and microbiological investigations did not lead to a documented source of infection.

Since the 2012 French outbreak, the epidemic clone A of $S$. clavata has been identified several times in France in small clustered or sporadic cases [19]. In Italy, three cases of G. clavatum bloodstream infections were reported in one hematological ward in 2016 [20]. All patients received cytarabine and developed G. clavatum infection within 3 weeks from therapy initiation. In all cases, visceral localizations (spleen, liver, and lung) were documented by a total body computed tomography scan. A prolonged antifungal therapy with high doses of liposomal amphotericin-B was necessary to obtain fever resolution; one patient did however die.

S. clavata, previously reported as G. clavatum, had rarely been isolated from human samples before this outbreak $[21,22]$. Its ecology, reservoir, and importance in agriculture and food are unknown [23]. This species is closely related to the known human pathogen Magnusiomyces capitatus (previously known as Geotrichum capitatum) and these two species are often misidentified. Both are resistant to echinocandins, which are recommended in hematology wards in case of candidemia or febrile neutropenia of unknown origin. Sporadic cases and outbreaks of fungemia due to $M$. capitatus have been reported in patients with acute hematological malignancies, and these outbreaks have sometimes been related to contaminated dairy products [18]. In the French S. clavata outbreak, results of local investigations of fungal contamination of food, blood products, medical devices, and environmental samples were all negative [18].

\section{Sarocladium kiliense}

An outbreak of Sarocladium kiliense, formerly Acremonium kiliense, bloodstream infections occurred from June 2013 to January 2014 and included a cluster of cases at eight hospitals in Santiago, Chile [24]. All 67 patients infected with $S$. kiliense were under chemotherapy and received the same antinausea medication (ondansetron), produced by the same pharmaceutical company in 
Colombia. Two out of three lots of unopened ondansetron, tested by the Chilean Ministry of Health, yielded vials contaminated with $S$. kiliense, forcing a recall of all ondansetron in Chile made by the Colombian manufacturer. Subsequently, Colombian officials discovered 16 other infected patients who received ondansetron also from the same Colombian pharmaceutical company. Culturing and conventional DNA sequence identification methods confirmed that ondansetron was contaminated with S. kiliense [24].

S. kiliense has been implicated previously in healthcarerelated infections, but the lack of available typing methods has precluded the ability to substantiate sources. The use of WGS-based typing to investigate fungal outbreaks has become integral to epidemiologic investigations. The WGS-based typing analysis demonstrated that the patient isolates from Chile and Colombia were nearly genetically indistinguishable from those recovered from the unopened medication vials, indicating the likely presence of a single-source infection [24].

In 2013 Ioakimidou et al. reported an unusual cluster of possible catheter-related bloodstream infections due to S. kiliense (A. kiliense) in patients who underwent hematopoietic stem cell transplantation [25]. Three febrile transplanted patients repeatedly yielded the fungus from blood cultures taken through a CVC during a short period of 1.5 months (March to May 2011) in a Hematology Department in Thessaloniki, Greece. The identification of S. kiliense was confirmed by sequencing the internal transcribed spacer (ITS) region of three isolates (one from each patient). In accordance with antifungal susceptibility testing, the patients received voriconazole in addition to CVC removal. The outcome was favorable for all the patients.

S. kiliense, a hyaline mold formerly known as Acremonium kiliense, is a ubiquitous soil saprophyte commonly found in the environment and occasionally infecting humans. Its pathogenicity in immunocompetent patients is low and usually is related to inoculation of the fungus via a penetrating injury that often leads to a granuloma formation. A. kiliense has been described as a cause of mycetoma, keratitis, endophthalmitis, endocarditis, continuous ambulatory peritoneal dialysis-associated peritonitis, and catheter-related fungaemia [25]. However, the presence of underlying immunological disorders can predispose to the development of a usually fatal systemic infection such as peritonitis [26].

\section{Exserohilum rostratum}

In September 2012, the CDC was notified of several cases of meningitis in Tennessee, including one patient with culture-confirmed Aspergillus fumigatus meningitis 46 days after an epidural steroid injection. This patient was the index case of the largest fungal infection epidemic in the United States, a public health threat of historically unprecedented magnitude.

Indeed, subsequent investigations revealed a multistate [23] outbreak of fungal infections, primarily Exserohilum rostratum, caused by epidural, paraspinal, and peripheral joint injections of fungus-contaminated lots of methylprednisolone acetate (MPA) produced by a single compounding pharmacy $[27,28]$. More than 13,000 people were exposed to three lots of contaminated MPA and in October 2013, 751 had developed fungal infections following their MPA injections and resulting in 64 deaths. Specimens from patients were tested for the presence of fungi, and laboratory evidence confirmed the presence of $E$. rostratum in 153 case patients (20\%). The fungal infection cases presented a broad spectrum of clinical disease, reflecting the differences in pathogenesis, exposure route, and host risk factors [29]. A total of 233 patients only had meningitis, 325 only had paraspinal/spinal infection, 33 only had peripheral joint infection, 151 had meningitis and paraspinal/spinal infection, two had paraspinal/spinal infection and peripheral joint infection, and seven had a stroke [30].

The overall attack rate was 5.5 cases per 100 exposed persons [28]. Case patients had received a median of one injection (range, 1-6) of implicated MPA lots, with a median age of 64 years (range, 15-97 years), and median incubation period of 48 days (range, 0-249 days) from the last injection to diagnosis [30].

Cohort analysis of patients who had been given epidural or paraspinal glucocorticoid injections in Tennessee showed that the infection risk was higher among patients exposed to: one specific lot among the three contaminated lots, older vials, higher doses, multiple procedures, and in patients in whom a translaminar approach to epidural glucocorticoid injection was used [27]. Tests carried out at CDC and Food and Drug Administration laboratories on the preservative-free MPA vials confirmed the presence of E. rostratum in unopened vials from two of the three recalled lots. These laboratory results strengthen the link between the preservative-free MPA vials and the outbreak resulting from a series of sterility assurance failures [31].

The major cause of this outbreak was E. rostratum, a dematiaceous (black) mold found in soil and plants debris worldwide, however it is more common in tropical and subtropical areas [27]. This black mold usually infects plants and rarely causes disease in humans. Of the approximately 30 cases of Exserohilum infections reported in the literature before this outbreak, the most common presentations were skin, corneal, and sinus infections [29]. Because Exserohilum rarely causes human infections, relatively little is known about its physiopathology and management, particularly in the case of central nervous system (CNS) infections. How 
the pathogen entered the CNS, in this outbreak, is unclear. It may be rarely by direct inoculation of the contaminated material into the subarachnoid space by inadvertent puncture of the dura during the glucocorticoid injection, or more likely, by direct contiguous spread from the site of injection.

\section{Whole-genome sequence typing: A New molecular tool for uncommon fungal outbreak investigations}

Whole-genome sequence (WGS) typing is a new molecular approach that enables genotyping of any microorganism without genetic insights or prior knowledge of the natural population diversity in that species. Thus, it can be used when no other conventional method is available for molecular genotyping. Indeed, when an outbreak is caused by an uncommon fungal species there is usually little epidemiological information available regarding dissemination, genetic diversity, and/ or population structure for the species; standard methods for molecular genotyping are often not suitable and lack comprehensive resolution. For these unusual fungal pathogens, WGS typing can be highly valuable for allowing first molecular comparisons of strains [32]. WGS typing is based on the analysis of whole singlenucleotide polymorphisms (SNPs) within each genome, which allows investigating genome-wide variation between isolates. The relationships between the isolates can then be inferred from the number of SNPs differing between them. SNP distances determine genetic relatedness. Another advantage of WGS typing is that it permits the production of "de novo assembly" for these unusual pathogens lacking published reference genomes. Whole-genome sequencing is also useful for getting information characterized important traits, such as the level of ploidy, the size of assembled genome, etc.

WGS typing has a high discriminatory power to relate strains. However, its current limitation is that it must be performed in a laboratory in which the different steps of the process are well established, including sequence acquisition and bioinformatics for handling and analysing the data [33]. Considerable challenges remain due to the lack of common standards, particularly for investigating fungal genomes because they are much larger than those of bacteria and viruses and have a variable level of ploidy.

Recent years have been rich in large fungal outbreaks caused by very unusual fungal species (Table 1). These outbreaks, due to either yeasts or mold, have signaled the beginning of a new era of fungal outbreak investigation based on the comparison of the whole genomes of outbreak strains by using WGS. WGS typing permits investigation into several fungal outbreaks due to uncommon fungal species allowing researchers to decipher epidemiological clues [34-36].
The largest fungal outbreak of healthcare-associated infections investigated using WGS typing was caused by the black soil mold E. rostratum, responsible for a number of cases of meningitis in the USA. Owing to epidemiological investigations, the use of MPA injections contaminated with $E$. rostratum was quickly demonstrated to be responsible for the outbreak [37, 38]. Different lots of MPA from a single compounding pharmacy were positive with E. rostratum. However, it was not possible to demonstrate the genetic relationship between the fungal isolates due to the lack of relevant typing methods for that given species. WGS typing was eventually used to analyse and compare the genomes of both the clinical isolates and those from MPA vials originating from different lots [39]. It initially demonstrated that the isolates were highly clonal, strongly suggesting a single common source. Secondly, it demonstrated that clinical isolates could not be distinguished from those from the MPA vials, confirming that MPA was the source of infection. Interestingly, WGS analysis also showed that these $E$. rostratum isolates were haploid and nearly identical, only differing by less than 2 SNPs between any pair of isolates. In contrast, hundreds of thousands of SNPs differentiated the isolates responsible for the outbreak and unrelated control isolates. These huge differences between unrelated and related genome strains unearths interesting questions and may indeed suggest that the unrelated control strains belonged to different cryptic species. Nonetheless, this study highlighted the power of the WGS typing to provide accurate information about the relatedness of the isolates of rare species, here E. rostratum, when no genetic information was available.

The same approach was then used to investigate the healthcare-associated outbreak of S. kiliense bloodstream infections associated with the administration of contaminated antinausea medication among oncology patients in Colombia and Chile [24]. Once again, WGS typing confirmed a common source of infections in the two countries related to the contaminated medication. Indeed, genomes of isolates from infected patients of the two countries and from the different lots of contaminated medication were nearly indistinguishable from one another. No more than 5 SNPs were detected between any pair of isolates; for reference the genome size of $S$. kiliense is approximately $36 \mathrm{MB}$.

In France, S. clavata, another previously unrecognized fungal pathogen, was implicated for different clusters of infections in leukemic patients [18]. The use of WGS typing identified a single clone for most cases. However, it was not possible to connect it to a common source of infection.

An interesting secondary outcome of these three studies was that a large panel of assembled genomes from the three species was produced for the first time. Some of them were from related strains, including genomes from 
the outbreak strains, while others were from unrelated control strains, from the same or different countries. These genome sequences served as the basis for constructing databases to study genetic variations in these unusual species, which had never been done before. Thus, in addition to their power for genotyping, WGS data generated during outbreak investigations can also to be used to better understand the biology, the virulence, and even possible therapeutic targets in these species.

Recently, the nearly simultaneous global emergence of a novel species of Candida, C. auris, capable of causing hospital-acquired multidrug-resistant infections, has likely represented one of the more complex challenges in terms of epidemiological investigation. In 2009, when C. auris was first isolated from the external ear canal in a Japanese hospital patient, no information about this species or its putative reservoir was available. Since the publication of the first $C$. auris genome sequence in 2015 [40], a large number of C. auris strains have been sequenced for investigating different outbreaks. Their analysis suggests that the pandemic is due to recent and independent emergences of different clonal populations of $C$. auris, rather than to the worldwide spread of a dominant clone. Indeed, phylogenetic analysis of the whole genome SNPs from strains isolated from three continents showed that there is a strong phylogeographic structure, with the strains grouping into unique clades by geographic regions [14]. The strains from the same geographic region, such as South Asia, South America, or South Africa, were highly clonal and belonged to a specific clade, with very few SNPs differences (16-70 SNPs). In contrast, tens of thousands of SNPs differentiated strains from different continents.

In addition, recent investigations showed that in a given country, strains isolated from patients hospitalized in different hospitals or towns can be virtually identical (only a few SNP differences) allowing precise tracking of clonal spreading in the different clusters. Finally, a recent study showed almost identical (less than 5 SNP differences) C. auris isolates from the surface environment of one hospitalized patient and his own isolates, which further suggested that the spread within health care settings was possible [41]. Overall, WGS exclusively provided unambiguous data on the genome sequences and on the number of SNPs differentiating isolates. Those can easily be shared between laboratories but also centralized for a global investigation of the pandemic [42]. As mentioned above for other uncommon species, these data have also been used to further study genetics of the biology and the virulence of C. auris [43].

\section{From infection control point of view}

The various fungal outbreaks described within the last 6 years have highlighted not only the importance of general infection prevention measures but also the importance of warning alert systems. Indeed, the specificity of these outbreaks emphasizes the value of monitoring systems. Concerning C. auris, the risk of misidentification was high and it has been suggested that $C$. auris should be suspected in several situations, such as: a) when identification cannot be obtained using traditional biochemical mycological methods, and b) when resistance to more than one antifungal drug is detected for an isolate with an ambiguous identification [44]. Furthermore, concerning the other described species such as $S$. clavata, E. rostratum, and S. kiliense, the published studies highlighted several points as the common source of contamination $(E$. rostratum and S. kiliense) and the specific populations at risk. It seems fundamental to introduce warning alert systems that could help practitioners and health authorities to react quickly to prepare in the event of an outbreak. These warning alerts could be implemented in specific populations e.g., immunosuppressed patients.

Given the risk of nosocomial transmission of C. auris, it is necessary to promptly implement infection control measures to limit its spread. Similar to other Candida species, colonized and infected $C$. auris patients share the same risk factors, including diabetes mellitus, abdominal surgery, broad-spectrum antibiotics, and presence of CVCs [17]. Healthcare acquired infections typically occur several weeks (10-50 days) into a patient's hospital stay [6].

Hand transmission and persistent contamination of environmental surfaces within healthcare facilities have been associated with outbreaks; thus, CDC recommendations are based on standard and contact precautions [45]. As for other Candida species, transmission could occur through healthcare workers (HCW) hands; however unlike others $\mathrm{HCW}$ seem not to be colonized long term. Indeed, as suggested by two different studies, carriage seems to be rare. The most recent study [46] highlighted that during an outbreak only four among $145 \mathrm{HCW}$ were hand carriers. However systematic sampling of the hands, nose, axilla, groin, and throat of 258 $\mathrm{HCW}$ conducted as part of the UK investigation identified only a single HCW with a positive nares swab, who later tested negative from the same site, suggesting transient carriage [15].

All hospitalized patients with $C$. auris infection or colonization should be housed in single rooms with environmental precautions. During outbreak investigations, $C$ auris has been isolated from medical equipment likely originating from patient's skin shedding [47]. Explaining why considerable attention has focused on the efficacy of disinfectants used for skin decolonization and environmental decontamination.

Indeed, several authors suggested that contaminated surfaces in healthcare facilities may be an important source of 
Table 2 Interventions needed in case of Candida auris outbreak

\begin{tabular}{ll}
\hline Interventions proposed & Usefulness \\
\hline 1-Notify public health agency & Undoubted \\
2-Place patient (colonized or infected) in a single room & Undoubted \\
3-Institute Contact Precautions for colonized or infected patients & Undoubted \\
4-Screen all contact patients (defined as roommates) once a week and before leaving the medical ward & Uncertainty how best to monitor \\
5-Reinforce environmental cleaning 3x day with 1000 ppm chlorine based, vaporized H2O2 & Undoubted \\
6-Reduce duration of invasive procedures in colonized patients & Undoubted \\
7-Skin decolonization (colonized patients) with 10\% w/w iodinated povidone & No clear data \\
\hline
\end{tabular}

acquisition [48-50]. Experimentally, C. auris and other Candida species persisted for 7 days or up to 4 weeks on moist and dry surfaces, respectively [51]. Moreover, $C$. auris exhibited a greater propensity to survive on surfaces than C. albicans, but not C. parapsilosis or C. glabrata. In comparison to common bacterial pathogens, Candida species were recovered with similar frequencies from dry surfaces and were recovered significantly more often from moist areas such as sinks. Moreover, $C$. auris has the capacity to form antifungal resistant biofilms sensitive to the disinfectant chlorhexidine in vitro [52]. Correspondingly, during an outbreak in London, Schelenz et al. [15] implemented extreme environmental decontamination measures for cleaning and disinfection of the patient rooms and equipment using $1000 \mathrm{ppm}$ chlorine-based products three times a day. On discharge or transfer of a C. auris positive patient, the room was subjected to terminal cleaning with 10,000 ppm chlorine-based detergent and all cleaned equipment was left in the room to be disinfected with hydrogen peroxide vapour.

The CDC recommends thorough daily and terminal disinfection of room surfaces and shared medical equipment in rooms of patients with $C$. auris infection (https://www.cdc.gov/fungal/diseases/candidiasis/ c-auris-infection-control.html). Although many disinfectants are registered as disinfectants against Candida species by the Environmental Protection Agency, it is recommended that a disinfectant effective against Clostridium difficile spores should be used, such as chlorine-based products.

Several recent studies evaluated the efficacy in vitro of disinfectants used for skin decolonization and environmental decontamination during hospital outbreaks [5355]. All showed differences between products; activity also varied with different formulations. Indeed, chlorhexidine gluconate, iodinated povidone, chlorine and $\mathrm{H}_{2} \mathrm{O}_{2}$ vapour demonstrated effective killing activity against $C$. auris when used in clinical practice. However, among disinfectants utilised for skin decolonization, chlorhexidine was much less inhibitory at $3 \mathrm{~min}$ contact time compared to iodinate povidone used at $10 \%$ [54]. Similarly, the widely used quaternary ammonium disinfectants had a relatively poor activity against all Candida species [55].

Limiting the spread of $C$. auris needs rapid multifaceted interventions (Table 2) including contact isolation, enhancing environmental disinfection, screening contact populations, and skin decolonization for colonized patients. However, there is uncertainty as to how best monitor prolonged colonization (https://www.cdc.gov/fungal/diseases/candidiasis/c-auris-infection-control.html). There are no clear data on the efficacy of decolonization measures for patients colonized with $C$. auris, although chlorhexidine has been tested for that purpose during outbreaks [15, 49].

\section{Conclusions}

Currently, invasive fungal infections have undoubtedly been identified as having a major negative impact on human health. Indeed, they are a real threat during the hospital course of the weakest. Data from epidemiological studies has allowed better identification of patients at risk and major prevention measures have been evaluated to decrease the global burden of fungal infections. However, when a new situation occurs, such as a healthcare outbreak due to a fungal species, it is difficult to evaluate which are the most appropriate control measures to implement rapidly, in part, because healthcare fungal outbreaks are rare phenomena. Nevertheless, during recent years we have suffered from four large healthcare fungal outbreaks due to uncommon and new species of fungi, which have been responsible for hundreds of infection cases. The analysis of these rare epidemic phenomena is a unique opportunity to learn how to rapidly identify the first cases, to implement adequate control measures even when published data are lacking, and to reinforce the awareness of the public health community with regards to this new fungal risk.

\footnotetext{
Abbreviations

CDC: Center for disease prevention and control; CVC: Central venous catheter; ECDC: European center for disease prevention and control; HCW: Healthcare workers; ICU: Intensive care unit; MALDI-TOF: Matrix-assisted laser desorption ionization-time of flight; MDR: Multidrug-resistant; MPA: Methylprednisolone acetate; WGS: Whole-genome sequencing; WGST: Whole-genome sequence-based typing
} 


\section{Acknowledgements}

Not applicable.

\section{Funding}

Not applicable.

\section{Availability of data and materials}

Not applicable.

\section{Authors' contributions}

$M E B, S B$ and JRZ analysed and interpreted the litterature regarding the healthcare associated fungal outbreaks due to new and uncommon species. $M E B, S B$ and JRZ were equal contributor in writing the manuscript. All authors read and approved the final manuscript.

\section{Ethics approval and consent to participate}

Not applicable.

\section{Consent for publication}

Not applicable.

\section{Competing interests}

The authors declare that they have no competing interests.

\section{Publisher's Note}

Springer Nature remains neutral with regard to jurisdictional claims in published maps and institutional affiliations.

\section{Author details}

${ }^{1}$ Unité de Parasitologie-Mycologie, Service de Microbiologie clinique, Hôpital Necker Enfants-Malades, Assistance Publique - Hôpitaux de Paris (APHP), Paris, France. ${ }^{2}$ Université Paris Descartes, Sorbonne Paris-Cité, Paris, France. ${ }^{3}$ Département Mycologie, Institut Pasteur, Unité Biologie et Pathogénicité Fongiques, Paris, France. ${ }^{4}$ Service de Parasitologie-Mycologie, Hôpital Avicenne, Groupe Hospitalier Paris-Seine-Saint-Denis, Assistance Publique Hôpitaux de Paris (APHP), Bobigny, France. ${ }^{5}$ Université Paris 13, Bobigny, France. ${ }^{6}$ Département de microbiologie clinique, unité de contrôle et de prévention du risque infectieux, Hôpital Avicenne, Groupe Hospitalier Paris-Seine-Saint-Denis, Assistance Publique - Hôpitaux de Paris (APHP), Bobigny, France. ${ }^{7} \mathrm{AMME}$, UMR 1137, Université Paris 13, Sorbonne Paris Cité, Paris, France.

\section{Received: 29 December 2017 Accepted: 21 March 2018}

\section{Published online: 27 March 2018}

\section{References}

1. Suleyman G, Alangaden GJ. Nosocomial fungal infections: epidemiology, infection control, and prevention. Infect Dis Clin N Am. 2016:30(4):1023-52.

2. Yiannakis EP, Boswell TC. Systematic review of outbreaks of Pneumocystis jirovecii pneumonia: evidence that $P$. jirovecii is a transmissible organism and the implications for healthcare infection control. J Hosp Infect. 2016;93(1):1-8.

3. Davoudi S, Graviss LS, Kontoyiannis DP. Healthcare-associated outbreaks due to Mucorales and other uncommon fungi. Eur J Clin Investig. 2015;45(7): 767-73.

4. Martins N, Ferreira IC, Barros L, Silva S, Henriques M. Candidiasis: predisposing factors, prevention, diagnosis and alternative treatment. Mycopathologia. 2014;177(5-6):223-40.

5. Arendrup MC, Patterson TF. Multidrug-resistant Candida: epidemiology, molecular mechanisms, and treatment. J Infect Dis. 2017;216(suppl_3):S445-51.

6. Chowdhary A, Sharma C, Meis JF. Candida auris: a rapidly emerging cause of hospital-acquired multidrug-resistant fungal infections globally. PLoS Pathog. 2017;13(5):e1006290.

7. US Center for Disease Control and Prevention. Global emergence of invasive infections caused by the multidrug-resistant yeast Candida auris. http://www.cdc.gov/fungal/diseases/candidiasis/candida-auris-alert.html. Accessed 24 June 2016.

8. Public Health England. Candida auris identified in England. https://www. gov.uk/government/uploads/system/uploads/attachment_data/file/534174/ Guidance_Candida_auris.pdf. Accessed 1 July 2016.
9. European Center for Disease Control and Prevention. http://ecdc.europa.eu/ en/publications/Publications/Candida-in-healthcare-settings_19-Dec-2016. pdf. Accessed 20 Dec 2016.

10. Satoh K, Makimura K, Hasumi Y, Nishiyama Y, Uchida K, Yamaguchi H. Candida auris sp. nov., a novel ascomycetous yeast isolated from the external ear canal of an inpatient in a Japanese hospital. Microbiol Immunol. 2009;53(1):41-4

11. Lee WG, Shin JH, Uh Y, Kang MG, Kim SH, Park KH, Jang HC. First three reported cases of nosocomial fungemia caused by Candida auris. J Clin Microbiol. 2011;49(9):3139-42.

12. Chowdhary A, Voss A, Meis JF. Multidrug-resistant Candida auris: 'new kid on the block' in hospital-associated infections? J Hosp Infect. 2016;94(3):209-12.

13. Kathuria S, Singh PK, Sharma C, Prakash A, Masih A, Kumar A, Meis JF, Chowdhary A. Multidrug-resistant Candida auris misidentified as Candida haemulonii: characterization by matrix-assisted laser desorption ionizationtime of flight mass spectrometry and DNA sequencing and its antifungal susceptibility profile variability by Vitek $2, \mathrm{CLSI}$ broth microdilution, and Etest method. J Clin Microbiol. 2015;53(6):1823-30.

14. Lockhart SR, Etienne KA, Vallabhaneni S, Farooqi J, Chowdhary A, Govender NP, Colombo AL, Calvo B, Cuomo CA, Desjardins CA, Berkow EL, Castanheira M, Magobo RE, Jabeen K, Asghar RJ, Meis JF, Jackson B, Chiller T, Litvintseva AP. Simultaneous emergence of multidrug-resistant Candida auris on 3 continents confirmed by whole-genome sequencing and epidemiological analyses. Clin Infect Dis. 2017;64(2):134-40.

15. Schelenz S, Hagen F, Rhodes UL, Abdolrasouli A, Chowdhary A, Hall A, Ryan L, Shackleton J, Trimlett R, Meis JF, Armstrong-James D, Fisher MC. First hospital outbreak of the globally emerging Candida auris in a European hospital. Antimicrob Resist Infect Control. 2016;5:35.

16. European Center for Disease Control and Prevention. Candida auris in healthcare settings. https://ecdc.europa.eu/en/publications-data/candidaauris-healthcare-settings. Accessed 20 Dec 206.

17. Clancy CJ, Nguyen MH. Emergence of Candida auris: an international call to arms. Clin Infect Dis. 2017;64(2):141-3.

18. Vaux S, Criscuolo A, Desnos-Ollivier M, Diancourt L, Tarnaud C, Vandenbogaert M, Brisse S, Coignard B, Dromer F, Geotrichum Investigation Group. Multicenter outbreak of infections by Saprochaete clavata, an unrecognized opportunistic fungal pathogen. MBio. 2014;5(6):e02309-14.

19. CNRMA 2012 activity report. https://www.pasteur.fr/fr/sante-publique/CNR/ les-cnr/mycoses-invasives-antifongiques/rapports-d-activite.

20. Del Principe MI, Sarmati L, Cefalo M, Fontana C, De Santis G, Buccisano F, Maurillo L, De Bellis E, Postorino M, Sconocchia G, Del Poeta G, Sanguinetti M, Amadori S, Pagano L, Venditti A. A cluster of Geotrichum clavatum (Saprochaete clavata) infection in haematological patients: a first Italian report and review of literature. Mycoses. 2016;59(9):594-601.

21. Guého E, de Hoog GS, Smith MT, Meyer SA. DNA relatedness, taxonomy, and medical significance of Geotrichum capitatum. J Clin Microbiol. 1987; 25(7):1191-4.

22. Lacroix C, Brethon B, Boissel N, Desnos M, Leblanc T, Raffoux E, Baruchel A, Dombret $\mathrm{H}$. Feuilhade de Chauvin M. Geotrichum clavatum: an emerging pathogen reponsible for invasive infection in two neutropenic leukemia patients. Turin: P180, 3rd Trends In Medical Mycology (TIMM); 2007.

23. De Hoog GS, Smith MT. Chapter 31 - Galactomyces redhead \&amp; Malloch (1977). In the yeasts (fifth edition). London: Elsevier; 2011. p. 413-20.

24. Etienne KA, Roe CC, Smith RM, Vallabhaneni S, Duarte C, Escadon P, Castaneda E, Gomez BL, de Bedout C, López LF, Salas V, Hederra LM, Fernandez J, Pidal P, Hormazabel JC, Otaiza F, Vannberg FO, Gillece J, Lemmer D, Driebe EM, Englethaler DM, Litvintseva AP. Whole-Genome Sequencing to Determine Origin of Multinational Outbreak of Sarocladium kiliense bloodstream infections. Emerg Infect Dis. 2016;22(3):476-81.

25. loakimidou A, Vyzantiadis TA, Sakellari I, Arabatzis M, Smias C, Douka V, Velegraki A, Anagnostopoulos A, Malissiovas N. An unusual cluster of Acremonium kiliense fungaemias in a haematopoietic cell transplantation unit. Diagn Microbiol Infect Dis. 2013;75(3):313-6.

26. Khan Z, Al-Obaid K, Ahmad S, Ghani AA, Joseph L, Chandy R. Acremonium kiliense: reappraisal of its clinical significance. J Clin Microbiol. 2011;49(6): 2342-7.

27. Kainer MA, Reagan DR, Nguyen DB, Wiese AD, Wise ME, Ward J, Park BJ, Kanago ML, Baumblatt J, Schaefer MK, Berger BE, Marder EP, Min JY, Dunn $J R$, Smith RM, Dreyzehner J, Jones TF, Tennessee Fungal Meningitis Investigation Team. Fungal infections associated with contaminated methylprednisolone in Tennessee. N Engl J Med. 2012;367(23):2194-203. 
28. Smith RM, Schaefer MK, Kainer MA, Wise M, Finks J, Duwve J, Fontaine $E_{c}$ Chu A, Carothers B, Reilly A, Fiedler J, Wiese AD, Feaster C, Gibson L, Griese S, Purfield A, Cleveland AA, Benedict K, Harris JR, Brandt ME, Blau D, Jernigan J, Weber JT, Park BJ, Multistate Fungal Infection Outbreak Response Team. Fungal infections associated with contaminated methylprednisolone injections. N Engl J Med. 2013;369(17):1598-609.

29. Chiller TM, Roy M, Nguyen D, Guh A, Malani AN, Latham R, Peglow S, Kerkering T, Kaufman D, McFadden J, Collins J, Kainer M, Duwve J, Trump D, Blackmore C, Tan C, Cleveland AA, MacCannell T, Muehlenbachs A, Zaki SR, Brandt ME, Jernigan JA, Multistate Fungal Infection Clinical Investigation Team. Clinical findings for fungal infections caused by methylprednisolone injections. N Engl J Med. 2013;369(17):1610-9.

30. Abbas KM, Dorratoltaj N, O'Dell ML, Bordwine P, Kerkering TM, Redican KJ. Clinical response, outbreak investigation, and epidemiology of the fungal meningitis epidemic in the United States: systematic review. Disast Med Public Health Prep. 2016;10(1):145-51.

31. Vijayakumar R, Saleh Al-Aboody M, Sandle T. A review of melanized (black) fungal contamination in pharmaceutical products-incidence, drug recall and control measures. J Appl Microbiol. 2016;120(4):831-41.

32. Alanio A, Desnos-Ollivier M, Garcia-Hermoso D, Bretagne S. Investigating clinical issues by genotyping of medically important Fungi: why and how? Clin Microbiol Rev. 2017;30:671-707.

33. Lesho EP. How next-generation sequencing might not transform infectious disease practice. Clin Infect Dis. 2016;62(8):1052-3.

34. Etienne KA, Gillece J, Hilsabeck R, Schupp JM, Colman R, Lockhart SR, Gade L, Thompson EH, Sutton DA, Neblett-Fanfair R, Park BJ, Turabelidze G, Keim P, Brandt ME, Deak E, Engelthaler DM. Whole genome sequence typing to investigate the Apophysomyces outbreak following a tornado in Joplin, Missouri, 2011. PLoS One. 2012;7(11):e49989. https://doi.org/10.1371/journal. pone.0049989.

35. Gillece JD, Schupp JM, Balajee SA, Harris J, Pearson T, Yan Y, Keim P, DeBess E, Marsden-Haug N, Wohrle R, Engelthaler DM, Lockhart SR. Whole genome sequence analysis of Cryptococcus gattii from the Pacific northwest reveals unexpected diversity. PLoS One. 2011;6(12):e28550. https://doi.org/10.1371/ journal.pone.0028550.

36. Engelthaler DM, Chiller T, Schupp JA, Colvin J, Beckstrom-Sternberg SM, Driebe EM, Moses T, Tembe W, Sinari S, Beckstrom-Sternberg JS, Christoforides A, Pearson JV, Carpten J, Keim P, Peterson A, Terashita D, Balajee SA. Next-generation sequencing of Coccidioides immitis isolated during cluster investigation. Emerg Infect Dis. 2011;17(2):227-32. https://doi. org/10.3201/eid1702.100620.

37. Andes D, Casadevall A. Insights into fungal pathogenesis from the iatrogenic epidemic of Exserohilum rostratum fungal meningitis. Fungal Genet Biol. 2013:61:143-5.

38. Lockhart SR, Pham CD, Gade L, lqbal N, Scheel CM, Cleveland AA, Whitney AM, Noble-Wang J, Chiller TM, Park BJ, Litvintseva AP, Brandt ME. Preliminary laboratory report of fungal infections associated with contaminated methylprednisolone injections. J Clin Microbiol. 2013;51(8):2654-61.

39. Litvintseva AP, Hurst S, Gade L, Frace MA, Hilsabeck R, Schupp JM, Gillece JD, Roe C, Smith D, Keim P, Lockhart SR, Changayil S, Weil MR, MacCannell DR, Brandt ME, Engelthaler DM. Whole-genome analysis of Exserohilum rostratum from an outbreak of fungal meningitis and other infections. J Clin Microbiol. 2014;52(9):3216-22

40. Sharma C, Kumar N, Meis JF, Pandey R, Chowdhary A. Draft genome sequence of a fluconazole-resistant Candida auris strain from a Candidemia patient in India. Genome Announc. 2015;3(4):e00722-15.

41. Vallabhaneni S, Kallen A, Tsay S, Chow N, Welsh R, Kerins J, Kemble SK, Pacilli M, Black SR, Landon E, Ridgway J, Palmore TN, Zelzany A, Adams EH, Quinn M, Chaturvedi S, Greenko J, Fernandez R, Southwick K, Furuya EY, Calfee DP, Hamula C, Patel G, Barrett P, MSD LP, Berkow EL, Moulton-Meissner H, NobleWang J, Fagan RP, Jackson BR, Lockhart SR, Litvintseva AP, Chiller TM. Investigation of the first seven reported cases of Candida auris, a globally emerging invasive, multidrug-resistant fungus - United States, may 2013 august 2016. MMWR Morb Mortal Wkly Rep. 2016;65(44):1234-7.

42. Lesho EP, Bronstein MZ, McGann P, Stam J, Kwak Y, Maybank R, McNamara J, Callahan M, Campbell J, Hinkle MK, Walsh EE. Importation, mitigation, and genomic epidemiology of Candida auris at a large teaching hospital. Infect Control Hosp Epidemiol. 2018;39(1):53-7.

43. Sharma C, Kumar N, Pandey R, Meis JF, Chowdhary A. Whole genome sequencing of emerging multidrug resistant Candida auris isolates in India demonstrates low genetic variation. New Microbes New Infect. 2016;13:77-82.
44. Mizusawa M, Miller H, Green R, Lee R, Durante M, Perkins R, Hewitt C, Simner PJ, Carroll KC, Hayden RT, Zhang SX. Can multidrug-resistant Candida auris be reliably identified in clinical microbiology laboratories? J Clin Microbiol. 2017:55(2):638-40.

45. CDC. Recommendations for Infection Prevention and Control for Candida auris. 2017. Available at: https://www.cdc.gov/fungal/diseases/candidiasis/cauris-infection-control.html.

46. Biswal M, Rudramurthy SM, Jain N, Shamanth AS, Sharma D, Jain K, Yaddanapudi LN, Chakrabarti A. Controlling a possible outbreak of Candida auris infection: lessons learnt from multiple interventions. J Hosp Infect. 2017:97(4):363-70

47. Tsay S, Kallen A, Jackson BR, Chiller TM, Vallabhaneni S. Approach to the investigation and management of patients with Candida auris, an emerging multidrug-resistant yeast. Clin Infect Dis. 2017; https://doi.org/10.1093/cid/cix744.

48. Vallabhaneni S, Kallen A, Tsay S, Chow N, Welsh R, Kerins J, Kemble SK, Pacilli M, Black SR, Landon E, Ridgway J, Palmore TN, Zelzany A, Adams EH, Quinn M, Chaturvedi S, Greenko J, Fernandez R, Southwick K, Furuya EY, Calfee DP, Hamula C, Patel G, Barrett P, Lafaro P, Berkow EL, MoultonMeissner H, Noble-Wang J, Fagan RP, Jackson BR, Lockhart SR, Litvintseva AP, Chiller TM. Investigation of the first seven reported cases of Candida auris, a globally emerging invasive, multidrug-resistant fungus-United States, may 2013-august 2016. Am J Transplant. 2017:17(1):296-9.

49. Calvo B, Melo AS, Perozo-Mena A, Hernandez M, Francisco EC, Hagen F, Meis JF, Colombo AL. First report of Candida auris in America: clinical and microbiological aspects of 18 episodes of candidemia. J Inf Secur. 2016; 73(4):369-74.

50. Tsay S, Welsh RM, Adams EH, Chow NA, Gade L, Berkow EL, Poirot E, Lutterloh E, Quinn M, Chaturvedi S, Kerins J, Black SR, Kemble SK, Barrett PM, Barton K, Shannon DJ, Bradley K, Lockhart SR, Litvintseva AP, MoultonMeissner H, Shugart A, Kallen A, Vallabhaneni S, Chiller TM, Jackson BR. Notes from the field: ongoing transmission of Candida auris in health care facilities - United States, June 2016-may 2017. MMWR Morb Mortal Wkly Rep. 2017:66(19):514-5.

51. Welsh RM, Bentz ML, Shams A, Houston H, Lyons A, Rose LJ, Litvintseva AP. Survival, persistence, and isolation of the emerging multidrug-resistant pathogenic yeast Candida auris on a plastic health care surface. J Clin Microbiol. 2017;55(10):2996-3005.

52. Sherry L, Ramage G, Kean R, Borman A, Johnson EM, Richardson MD, Rautemaa-Richardson R. Biofilm-forming capability of highly virulent, multidrug-resistant Candida auris. Emerg Infect Dis. 2017;23(2):328-31.

53. Abdolrasouli A, Armstrong-James D, Ryan L, Schelenz S. In vitro efficacy of disinfectants utilised for skin decolonisation and environmental decontamination during a hospital outbreak with Candida auris. Mycoses. 2017:5. https://doi.org/10.1111/myc.12699.

54. Cadnum JL, Shaikh AA, Piedrahita CT, Sankar T, Jencson AL, Larkin EL, Ghannoum MA, Donskey CJ. Effectiveness of disinfectants against Candida auris and other Candida species. Infect Control Hosp Epidemiol. 2017;38(10): 1240-3.

55. Moore G, Schelenz S, Borman AM, Johnson EM, Brown CS. The yeasticidal activity of chemical disinfectants and antiseptics against Candida auris. Hosp Infect. 2017;30

\section{Submit your next manuscript to BioMed Central and we will help you at every step:}

- We accept pre-submission inquiries

- Our selector tool helps you to find the most relevant journal

- We provide round the clock customer support

- Convenient online submission

- Thorough peer review

- Inclusion in PubMed and all major indexing services

- Maximum visibility for your research

Submit your manuscript at www.biomedcentral.com/submit
C) Biomed Central 